\title{
Los mitos de la masculinidad \\ y de la feminidad en \\ El señor de los cielos
}

\author{
Nataly Guzmán \\ Universidad Centroamericana \\ "José Simeón Cañas", UCA \\ Andrea Cristancho \\ Universidad Centroamericana \\ "José Simeón Cañas", UCA
}

Resumen: Este artículo estudia cómo el producto mediático resultante de la fusión del melodrama con las series de acción construye las características de la identidad de género en El señor de los cielos y las representaciones ligadas a lo que significa ser hombre o mujer. Las narrativas de género de esta llamada "súper serie" exploran la relación entre género y naturaleza versus la construcción social de la masculinidad y de la feminidad, la capacidad de agencia humana de los personajes y las situaciones que son descritas como producto del destino.

Palabras claves: género, agencia humana, identidad, medios, representaciones

Abstract: This article studies how a media product resulting from a combination between melodrama and action series establishes a number of features connected with gender identity in El señor de los cielos, as well as the representations related to what it means to be a man or a woman. The gender narratives of this so called "super series" explore the relation between gender and nature versus the social construction of masculinity and femininity, the capacities associated with human agency, and the situations described as a result of destiny.

Keywords: gender, human agency, identity, media, representations 
Rutila Casillas, la hija mayor del señor de los cielos, crece observando cómo su madre padece la voluntad de su padre: no puede dar un paso sin que él la autorice. Solo tiene permitido moverse dentro del mundo de lujos domésticos que le ha sido provisto. Por eso Rutila decide que cuando crezca su vida será "diferente". Tratará de tomar las riendas de su destino con todo el poder que el apellido de su padre le confiere, pero aspirará secretamente a no ser dependiente, atormentada y sometida como su madre. Cuando crece, descubre que ser un tipo de mujer completamente opuesto a quien le dio la vida no es ninguna garantía para que nadie la reclame como propiedad.

Este artículo pretende analizar a partir de qué características se puede afirmar que las representaciones de género de El señor de los cielos, teleserie que se anuncia como novedosa por incorporar dinámicas audiovisuales llenas de acción y temas controversiales, tienen un trasfondo saturado de narrativas tradicionales, conservadoras y hasta míticas sobre la feminidad y la masculinidad. Por ello, se busca establecer qué tipo de narrativas de género construye El señor de los cielos en tres niveles principales: qué elementos de lo masculino y lo femenino son señalados como producto de la naturaleza; qué aspectos de la vida son planteados como parte de la capacidad de agencia humana, y qué situaciones son descritas como resultado del destino.

En la serie, los personajes tienden a calificar muchas de las características, reacciones y acciones de ellos mismos y de los demás a partir de si se es hombre o se es mujer. Parecería que hay una explicación biológica sobre el porqué de sus acciones, a pesar de que todos están de alguna manera al tanto de la influencia que ha tenido en ellos su experiencia de vida y el contexto en el que se mueven. Sin embargo constantemente se remiten a mundos femeninos o masculinos de esencias establecidas de comportamiento que justifican sus actos o que explican sus reacciones.

Para Raewyn Connell (2000, p. 12), ni la masculinidad ni la feminidad vienen programadas en los genes “ (...) ni son un elemento fijo de la estructura social previo a la interacción social. Se producen de forma activa, al utilizar los recursos y las estrategias disponibles en un escenario social determinado". Sin embargo, en el universo de Aurelio Casillas, la naturalización de las características de hombres y mujeres es el punto de certeza más grande desde el cual los personajes construyen sus representaciones de género.

Estas características predeterminadas atribuidas a los hombres $\mathrm{y}$ a las mujeres se establecen a 
través del lenguaje en los diálogos sostenidos por los personajes, y se materializan a través de representaciones particulares que construyen significados sobre la feminidad, la masculinidad y las relaciones de género. Por ejemplo, en la serie a las mujeres casi siempre se les reprochan acciones que en los hombres son vistas como aceptables: tener varias parejas, dejar a los hijos para salir a trabajar o tener un carácter fuerte. De acuerdo con Stuart Hall (2013, p. XXVI), las representaciones tienen que ver con la producción de significado “(...) a través del lenguaje, a partir de los conceptos que tenemos en la mente". En El señor de los cielos, las características y los roles de género están ligados a concepciones tradicionales que trazan un marco de ciertos límites preestablecidos. Los hombres tienen la posibilidad de forjar su destino, son los proveedores de la casa, inician proyectos sin ser necesariamente cuestionados y ayudan a su familia a salir adelante. A las mujeres constantemente se les recuerda que no son nadie sin la protección de un hombre, y que no pueden realizar proyectos sin la aprobación de sus parejas o sus padres. La narrativa de la serie señala que el deseo de ser madre es "natural" en la mujer, así como la capacidad de cuidar de los hijos, amar a un esposo, velar por un hogar y vivir "como cualquier persona normal", aunque se esté hablando de mujeres que viven de formas no tradicionales dentro del mundo del narcotráfico.

De esta forma, en la serie se puede apreciar en general cómo las representaciones de masculinidad están ligadas directamente al poder, al instinto y a la autoridad, y cómo las representaciones de feminidad a su vez están asociadas con el amor romántico, la corporalidad y la maternidad. Los hombres autorizados para vivir al máximo dentro de su condición de género son los que tienen control de las vidas de otros, poseen recursos económicos infinitos y pueden hacer su voluntad en cualquier situación sin ningún temor porque su instinto los hace colocar cada pieza en su lugar. Las mujeres que sobreviven a los peligros que implica el "negocio" familiar, se mantienen firmes cuando tienen muy claro la obediencia que les reclaman sus lazos de sangre, y cuando recurren, ya sea a su corporalidad para establecer relaciones convenientes, o a sus afectos para nutrir las alianzas de parentesco que las sostienen en el día a día. Para Hall (2013, p. XXV), las representaciones permiten interpretar el mundo, y los medios de difusión masiva proporcionan toda una serie de ejemplos sobre este tema.

Así pues, los significados que se le atribuyen a las concepciones sobre el ser hombre o ser mujer intervienen en la interpretación que se hace 
de las relaciones de género y de la conducta de las personas. Dentro del imaginario de El señor de los cielos, el hombre es propietario y la mujer es propiedad. Los que no sepan hacer valer su autoridad, la pierden; y las que no reconocen que su condición de "ser" es otorgada por una figura masculina, ponen su vida en un riesgo inminente. Según Kenneth MacKinnon (2003, p. 23), existe el temor de que la cultura popular tiende en general a alimentar las representaciones de los estereotipos más que a desafiarlas. En este trabajo, la discusión de los temas señalados no tiene como finalidad distinguir elementos de ficción para diferenciarlos de la realidad de la vida cotidiana, sino identificar qué tipo de representaciones de género asociadas a determinados mitos se encuentran arraigadas en el imaginario mediático a partir de formas específicas de ser hombre o ser mujer dentro de la narrativa que la serie en cuestión presenta.

Para Roland Barthes (1991, p. 143), el mito "(...) le da a las cosas una justificación natural y eterna, las dota de una claridad que no tiene que ver con las explicaciones sino con la enunciación de hechos, (...) anula la complejidad de las acciones humanas y les otorga la simpleza de las esencias". En El señor de los cielos, aún y cuando las acciones de muchos de los personajes masculinos son inaceptables, ya sea por comportamientos violentos, agresivos 0 transgresores, estas se explican a partir de una forma "natural" que tienen los hombres de reaccionar. Mientras que las actitudes que adoptan las mujeres se le atribuyen al predominio de lo emocional y lo sentimental en ellas. La forma en que los personajes establecen las relaciones de género parte de la manera como construyen sus representaciones de lo femenino y de lo masculino. Y su autopercepción está marcada, desde el punto de vista de los hombres, por sus decisiones $y$, desde la perspectiva de las mujeres, por el "destino" que les ha tocado vivir; así, dichas representaciones de género tienden a tornarse lineales $y$ distorsionadas a tal punto que son naturalizadas como cuestiones sin variantes posibles. Hasta cuando los personajes buscan cambiar sus prácticas sociales, salirse del narcotráfico o aspirar a una vida alejada de persecución y la violencia, ellos mismos insisten en la poca probabilidad de lograr anular una suerte que consideran predeterminada. Aurelio Casillas constantemente le recuerda a su familia, a sus mujeres, a sus empleados y a sus socios que nadie que entra en "el negocio" puede salirse de él. Como hecho determinante de esta afirmación, les explica con simpleza que así es la vida de quienes lo rodean, y que la muerte es, en todo caso, la única alternativa posible. Los mitos asociados al tema de género no residen en el hecho de si es verdad o mentira que la mujer nació para ser madre o que el hombre 
nació para imponerse con violencia. El mito es la simplificación, en este caso, de la condición de género, la naturalización de los estereotipos y la distorsión de los significados.

Dentro de este contexto, por lo tanto, la pregunta sobre si resignarse a un destino previsto para no perder la vida, o si abandonarlo todo bajo el riesgo de entrar en un círculo de persecuciones y violencia pone en cuestión el tema de la agencia humana. Para Giddens (1984, p. 9), la agencia está relacionada con el poder del sujeto de realizar acciones concretas, es decir, decidir si actuar de una manera u otra, porque "el término 'agencia' no se refiere a las intenciones que tienen las personas de hacer cosas, sino a la capacidad de hacer las cosas (...) La acción es un proceso continuo, un flujo, en el cual el monitoreo reflexivo que el individuo mantenga es fundamental para el conjunto de aspectos con los que los actores generalmente deben lidiar en el día a día". La serie muestra tanto a individuos que no se atreven a cambiar su destino como a sujetos que sí lo hacen. Aurelio Casillas es presentado como un individuo decidido siempre a actuar ante una situación. Sus socios o colaboradores también reaccionan a través de los criterios que impone Casillas. Sin embargo, de forma muy irónica, los que deciden retar a la suerte, ir contra Casillas y ejercer su capacidad de agencia humana, muestran que solo lo hacen para no darle el gusto al señor de los cielos de acabar con ellos en el momento que él lo decide, sino hasta que ellos no tengan más fuerzas para correr. Por ende, tanto hombres como mujeres, o cobardes como valientes, ven su capacidad de agencia solo como un mecanismo temporal que retarda una secuencia de hechos que tarde o temprano ocurrirá de todas maneras.

El señor de los cielos, en apariencia, rompe con el molde del melodrama clásico porque muestra facetas atrevidas y ocultas de sus personajes, aborda tópicos controversiales, discute temáticas sobre problemas sociales e institucionales y maneja un lenguaje directo y soez. Se anuncia en promocionales televisivos que hablan de nuevas concepciones de hombres y mujeres que no son los "típicos" protagonistas de "cara bonita", sino personas en control de su vida y sus acciones. Pero al mirar de cerca esta narrativa, mitad serie mitad melodrama, se pueden identificar o develar aquellos aspectos que recubren muchas de las representaciones de género más clásicas, limitadas y lineales. Entre otros programas de la misma categoría de El señor de los cielos, denominados específicamente como "super-series", están La reina del Sur, Señora Acero y El Chema, que han contado con un alto nivel de audiencia en toda Latinoamérica y entre la comunidad hispana de los Estados Unidos. 


\title{
Lo masculino y lo femenino como factores determinados por la naturaleza
}

\author{
El encuentro con el mito se da a través de un lenguaje inocente, \\ no porque sus intenciones estén ocultas (...) sino porque se naturalizan. \\ Roland Barthes, Mitologías.
}

En El señor de los cielos, que ha permanecido en el aire con siete temporadas desde 2013 hasta la fecha de hoy, Aurelio Casillas es el traficante de drogas más buscado del continente, pero también es un modelo aspiracional de masculinidad para aquellos que buscan dinero, conexiones, mujeres y poder. En la serie, muchos hombres buscan trabajar para él con la finalidad de salir de la miseria; mientras que otros desean asociarse con el capo para enriquecerse todavía más. Su existencia está dividida entre breves momentos de vida cotidiana con sus parejas, su madre y sus hijos, e intensas jornadas de acción, peligro y persecuciones espectaculares en las que desarrolla sus actividades de narcotráfico. El poder de Casillas se multiplica a partir de las personas que trabajan para él en el negocio del narcotráfico, desde sus hombres de confianza hasta todo tipo de autoridades que le facilitan su trabajo, pasando por figuras políticas que contribuyen a su encubrimiento y a sus múltiples operaciones ilícitas.

La masculinidad de Casillas no solo queda explicada en la narrativa a partir de su poder, sino a partir de sus despliegues de violencia gráfica, una violencia descrita como "natural" en él. Su madre afirma que desde pequeño fue pendenciero y que por eso siempre pudo imponerse y salir adelante. En la serie, su implacable violencia física está directamente relacionada con su "olfato" para detectar peligros potenciales, por lo que a pesar de presentar al personaje como un gran estratega de la distribución de mercadería ilícita, su aplastante capacidad para lidiar con todo tipo de situaciones, ya sea adversas o exitosas, se le atribuye a la "maña" de su instinto. Así, El señor de los cielos aparentemente no necesita pensar, pues nació en un mundo donde solo se sobrevive y se llega a la cima si se es capaz de desarrollar los instintos al máximo. Por ello, Casillas se ríe de todo lo que se llame inteligencia, ya que él mismo afirma que, aunque se considera un tipo listo y racional, su poderío está basado más que en la experiencia, en una capacidad nata que solo ciertos hombres poseen para medir fuerzas.

Otro factor que se explica como natural en Casillas es su aparente devoción por su familia. Aurelio se describe a sí mismo como un padre devoto, siempre preocupado por la seguridad de su madre, de su mujer 
en turno y de sus descendientes. De acuerdo con Casillas, su amor por la familia es innegociable porque se ve reflejado plenamente en el hecho de ser un padre responsable y proveedor de su hogar; pero también señala constantemente que tal dinámica le permite decidir el destino de cada miembro de su estirpe. El poder espectacular que despliega en el ámbito público se extiende hacia el espacio privado de su casa. Los hijos varones lo veneran, lo obedecen y lo respaldan en sus actividades de narcotráfico, y sus hijas lo cuestionan permanentemente porque no supo ser un buen esposo cuando vivía su madre, pero también afirman que "lo Casillas se lleva en la sangre", refiriéndose al hecho de que todos los hijos de Aurelio, incluidas ellas, han heredado de él su actitud violenta e impositiva, su habilidad con las armas, su necesidad de adrenalina y su tendencia a la promiscuidad.

Su aclamada naturaleza de padre y proveedor se mezcla con la imagen del villano que transgrede la moral y la ley; pero la idea del buen padre y del hombre al que la naturaleza ha provisto de una fortaleza inquebrantable, en todo momento tiende a diluir la idea del criminal. La figura de Aurelio transita entre villano y héroe dentro de la narrativa de la serie, y esa figura dual genera o construye un personaje que dentro de la ficción tiene una masculinidad llena de matices. Esa combinación genera en apariencia un personaje multidimensional que no puede clasificarse inmediatamente en las conocidas categorías de malo o bueno del melodrama tradicional, pero que si se mira de cerca se puede apreciar que Aurelio le pone un precio a cada buena acción que realiza, y no se rinde hasta cobrarlo. Para sostener esta postura, se le atribuye al personaje un vínculo indisoluble con una naturaleza que lo creó de esa manera excepcional, así como creó también a los diferentes hombres que trabajan para él como seres fuertes pero desaventajados, porque nacieron para servir a otros.

Por otra parte, dentro de esta teleserie, casi todas las figuras femeninas quedan unificadas principalmente por lazos también asociados con la naturaleza: su capacidad biológica de ser madres, su deseo inquebrantable de vivir la maternidad, su cuerpo y su vulnerabilidad generalizada de rendirse ante la posibilidad de una relación amorosa. En la narrativa, las mujeres quedan divididas en polos opuestos de identidades asociadas a la defensa de valores éticos versus identidades vinculadas a la posesión de un poder cuestionable; sin embargo todas quedan marcadas por una emotividad que establece la existencia de designios calificados como "naturales". Tal es el caso de la madre de Aurelio, quien no está de acuerdo con las operaciones ilícitas de su hijo, pero siempre que lo abandona para no ensuciarse con sus crímenes regresa porque alguien 
tiene que cuidarlo a él y a sus nietos. Para ella, las amantes van y las amantes vienen, pero una madre siempre está con sus hijos para alimentarlos, preocuparse por ellos, esperarlos en el único lugar al que se le puede llamar "hogar" (solo si existe la presencia de una madre) y para lavar sus heridas cuando están lastimados por la violencia que enfrentan día a día en el negocio al que entraron.

En El señor de los cielos, además de las mujeres de hogar, representadas principalmente por la madre de Aurelio y por la difunta esposa de éste. También se manifiesta la figura de la mujer del mundo del narcotráfico. Entre estas se encuentran una serie de mujeres comunes que son empleadas como prostitutas en fiestas y reuniones, y mujeres de cierto rango superior como Rutila, la hija mayor de Aurelio, y Mónica, la amante principal de él, quienes están involucradas en los negocios de Casillas. Las dos se sienten poderosas porque manejan grandes cantidades de dinero y se conducen con seguridad porque siempre están protegidas por un séquito de guardaespaldas. Ambas son rubias, usan maquillaje recargado, joyas costosas y visten ropa de diseñador extravagante y ajustada. Son mujeres calculadoras, astutas e inteligentes, sin embargo, consideran que su mejor arma es su cuerpo, por lo que utilizan su sexualidad para ganar poder y negociar con los enemigos poten- ciales. Expresan que a los hombres se les domina por medio de los instintos, y qué mejor que dejar que la naturaleza haga su trabajo; mientras sus hombres encuentran placer, ellas establecen nuevos instrumentos de alianza y obtienen nuevas cuotas de poder. Para salvar su vida, Rutila se involucra con el peor enemigo de su padre y, cuando este intenta acorralarla, le dice que nunca podrá hacerle daño, porque está esperando un hijo de él. Y Mónica le pide a Aurelio infinidad de veces que le perdone la vida aludiendo al hecho de que es la madre de su hijo menor.

Dentro de todo el glamour que las rodea y de su imagen hipersexualizada, tanto Rutila como Mónica constantemente señalan que en el fondo son como "cualquier" mujer y que sobre todo son madres, un don de la naturaleza que las nivela con el resto de las mujeres que han vivido esta experiencia de amor incondicional. Para ambas, sus hijos representan ese deseo de vivir que según ellas, ya habrían perdido sin sus pequeños. Las dos revelan constantemente que lo que más desean es tener estabilidad, enamorarse, tener un hogar, ser madres plenas y vivir sin temor a ser despojadas de la custodia de sus hijos. Este escrito no pretende poner en duda el amor materno o el valor de la familia, sino mostrar cómo esta serie, entre otras, establece de forma reiterada que los elementos que por excelencia definen la vida de la mujer 
son la maternidad y el amor de una pareja. Lo mismo ocurría en el caso de la única esposa que tuvo Aurelio, Jimena, madre de Rutila, quien afirmaba constantemente que lo único que la impulsaba a luchar por la vida eran sus hijos, pero hasta el día de su propia muerte, la única manera que encuentra para salvarlos es estableciendo alianzas amorosas que le permitan que un hombre $u$ otro la rescate de la tiranía de Aurelio.

Además de la figura materna y de la mujer del mundo del narcotráfico, se encuentra en la serie la imagen de la mujer profesional, como es el caso de Leonor Ballesteros, agente policial contratada para atrapar al señor de los cielos. Ella ha sido parte de un equipo de mujeres que han logrado infiltrarse en las operaciones de los cárteles con mucho éxito. Leonor se presenta como una mujer que posee un alto nivel de destreza corporal, una gran capacidad en el manejo de las armas, una habilidad extrema para conducir motocicletas y vehículos a toda velocidad, y una tendencia a buscar relaciones de una noche para relajarse de las exigencias de su trabajo. En todo momento se destaca que su habilidad ha sido adquirida a través del entrenamiento, contrario al caso de Aurelio, de quien se dice constantemente que sus destrezas corporales son naturales. A pesar de que Leonor es una mujer con una ética a prueba de todo, después de perseguir a Aurelio por años, es seducida por este y la pasión instintiva que despierta en ella la hace perder su voluntad, por lo que poco a poco se retira de manera ambigua del caso, especialmente cuando encuentra el amor con un candidato a la presidencia de México.

Leonor, mujer soltera y sin hijos, se encuentra entre los polos aparentes de la mujer asexuada y de la mujer erotizada, pero a medida que construye su devenir, termina con su carrera por haberse enamorado del hombre equivocado. Su vulnerabilidad sentimental "natural de mujer" la traiciona, y a pesar de toda su fuerza, su preparación y su entrenamiento, parece mostrar cómo todas las mujeres quedan en un mismo nivel y sin distinción de casos cuando sucumben al amor romántico o a la atracción sexual. El poder en los negocios que dicen buscar Mónica y Rutila, y el poder para acabar con el narcotráfico que intenta sustentar Leonor se convierten en aspiraciones ficticias que encubren los sueños románticos de estas mujeres.

Así, la forma de ser de hombres y mujeres queda explicada en la narrativa con frecuencia a partir de características determinadas por la naturaleza. Se reitera la idea de que si una mujer quiere armarse de valor, manejar armas, entrenarse para pelear, dar órdenes y resolver sus propios problemas es porque "los tiene bien puestos", "tiene pantalones", o porque "cree que es hombre". 
En la serie, constantemente aparece la necesidad de explicar, a partir de algunas acciones de las mujeres, que existe una tendencia por parte de ellas a adoptar un comportamiento que busca imitar características que solo los hombres poseen porque son naturales en ellos desde el nacimiento, pero no en ellas. Por otra parte, en El señor de los cielos también se indica que es una práctica natural que los hombres tengan múltiples parejas, que se alcoholicen, que compitan con otros por el afecto de una mujer o que usen la violencia, y se hace énfasis en afirmaciones despectivas tales como: “ipor qué lloras como mujercita?", "ipareces vieja!" “¿qué no eres macho?”, con la intención de indicar que una persona del sexo masculino se "rebaja" si no se apropia de su supuesta naturaleza violenta e indiferente.

\section{La agencia humana versus el destino}

Cada vez que Aurelio Casillas comenta cómo se inició en el mundo del narcotráfico, explica que desde jovencito supo que quería salir adelante por sus propios medios para hacerse cargo de su familia luego de perder a su padre, y que por eso tomó la decisión de dedicarse "al negocio". Señala con frecuencia que prácticamente él inventó el narcotráfico a gran escala, y que les abrió las puertas a todos los que hoy se dedican a lo mismo. A lo largo de la historia, aparecen varias escenas que muestran cómo Casillas superó en hazañas, estrategias y recursos a la generación anterior de narcotraficantes con la que creció. Su suegro, Don Cleto, otro capo, incluso le recriminó en muchas ocasiones que sólo se había casado con su hija para robarle mercado y asegurarse que su familia estuviera protegida de cualquier venganza.
Dentro de la serie, Casillas considera que su condición de hombre, padre, hijo y amante lo autoriza no solo a cuidar de las exorbitantes cantidades de dinero que gana y de los territorios que tiene controlados para operar, sino que también piensa que tiene derecho a decidir sobre la vida de sus hijas, su esposa, su mamá, sus amantes y sus socias. Esta perspectiva lo lleva, tanto a él como a sus enemigos, a ver a las mujeres relacionadas con él como propiedad y como posible mercancía intercambiable. Mientras que Aurelio percibe a las mujeres en su vida como piezas de su imperio, sus enemigos las ven como los puntos débiles de Casillas. Por ello sus competidores en el mundo del narcotráfico utilizan a las figuras femeninas presentes en la vida del señor de los cielos para perpetrar venganzas en su contra. Estas mujeres son un constante 
blanco de secuestro, persecución, violación, muerte y desaparición.

Rutila Casillas es un ejemplo importante de esta percepción de la mujer. De niña fue sometida y maltratada por el antiguo administrador de los bienes de Aurelio, el "Turco", cuando la madre de esta entabla una relación amorosa con él y huyen para escapar de Casillas. De adolescente, su novio la vende con engaños a uno de los grandes enemigos de Aurelio, el Chema Venegas; y cuando se convierte en la mujer de este último, los enemigos del Chema la secuestran y la violan para ejecutar su venganza contra él. Rutila es una mujer canjeable, la utilizan para hacer negociaciones y la tratan como una mercancía que tiene un valor limitado a su belleza y a su condición de hija de uno de los hombres más poderosos del narcotráfico. En este contexto Rutila se resiste en muchas ocasiones a entrar como socia en ese mundo, pero termina por ceder porque piensa que es su destino estar en ese ambiente. Por su parte, Mónica Robles, sucumbe ante Aurelio cuando acepta que su destino está marcado por amarlo irremediablemente, y por eso hasta lo perdona cuando se da cuenta que fue el propio Casillas quien mató a sus hermanos, su única familia. A pesar de ser una mujer sofisticada y poderosa, siempre se mantiene como una sombra cerca de Aurelio. Este, a su vez, la prostituye para que lo ayude a cerrar tratos en sus nego- cios, por lo que Mónica se asume como propiedad de Aurelio al pensar que gran parte del poder que ella ostenta no radica en su capacidad de negociación, sino en la lujuria que despierta su cuerpo, un cuerpo que le pertenece al señor de los cielos.

Tanto para Mónica como para Rutila, el camino que toman sus vidas es un porvenir trazado por los hombres de su familia, los hombres que las enamoran, sus enemigos o sus socios. $Y$ cuando se desmorona el mundo de sus hombres se cae a pedazos el mundo de ellas. En la serie, la suerte de la mujer está echada desde que nace, por lo que siempre debe cumplir con un destino previamente trazado y marcado por su emotividad y sus deseos afectivos. Para ambas, una naturaleza ligada a su capacidad de amar es lo que las hace sucumbir ante cualquiera de los elegidos de su corazón y cometer errores. Lo mismo sucede con la madre de Aurelio, quien se interna en un convento cuando es engañada por El Feyo Aguilera, quien la sedujo para vengarse de Casillas. La repetición de ese proceso, y la reiteración de la misma idea está presente también en otras teleseries: en Señora Acero, el personaje protagónico, Sara Acero, considera que nunca fue su intención introducirse en el narcotráfico, sino que fue el destino el que la puso en esa situación cuando muere su esposo. Por ello se busca un "padrino", un hombre que la proteja en sus operaciones de 
lavado de dinero, pues solo de esa forma podrá pagar el tratamiento contra la diabetes que necesita su hijo. Así también, en La reina del Sur, Teresa Mendoza asume como destino su incursión en el narcotráfico tras el asesinato de su pareja; considera que no le queda más alternativa que sobrevivir imitando el comportamiento despiadado de sus enemigos para sobrellevar el abismo al que la llevó el amor.

En El señor de los cielos, como en otras series y telenovelas, hay una idea muy limitada del significado de la agencia humana para la mujer. Parecería que los personajes femeninos entienden que tienen un poder relacionado con lo material, la posesión de recursos económicos o lujos, guardaespaldas, armas, dinero, propiedades, amantes y transportes sofisticados; también logran desarrollar mecanismos que les permiten ver que tienen la posibilidad de dominar a un enemigo, o de vengarse de sus agresores. Son mujeres que ganan cuotas de poder, pero a la larga este poder no las saca de su condición de propiedad, y no dejan de ser objeto de transacción. En muchas ocasiones estas mujeres piensan cómo salirse del círculo vicioso que las envuelve; sin embargo, optan por descartar cualquier acción concreta para tener una vida distinta de aquella que las oprime, y son ellas las que autocensuran sus aspiraciones. Con frecuencia justifican su falta de iniciativa para cambiar su realidad al describirse como prisioneras de pasiones irremediables por las que deben pagar un precio, o como esclavas de la "adrenalina" que les provoca el peligro y los riesgos del negocio. No hacen uso de su capacidad de agencia humana como dispositivo transformador de su vida, y señalan que el destino con el que deben cumplir hace que sea imposible para ellas lidiar con las circunstancias que les arrebatan su dignidad. Su capacidad de acción se ve limitada a involucrarse cada vez más en el mundo del narcotráfico y a una rebeldía que solo termina por ponerlas en un peligro mayor del que ya están dentro del ambiente en el que se mueven. Desde tal perspectiva, las narrativas en cuestión hacen énfasis en que la causa principal de la vulnerabilidad de todas estas mujeres radica en su mismo sexo.

De forma contraria, en esta serie los hombres mencionan constantemente que ellos toman sus propias decisiones, ya sean guardaespaldas o capos de la droga, en sus diálogos los personajes masculinos siempre se autodescriben como dueños de sus vidas. Por parte de aquellos que buscan salir de la pobreza para incorporarse a las filas del narcotráfico, en todo momento están claras las relaciones de dependencia que establecen con sus patrones, pero no se les califica ni se auto-perciben como propiedad de nadie, sino más bien como seres que deben estar dispuestos a dejar la vida en el 
cumplimiento de sus obligaciones. Si le cumplen al patrón, manejan la idea de que están haciendo su trabajo, porque son "de palabra". A estos hombres menos aventajados sus patrones les recuerdan constantemente quién manda, pero se habla más de una relación de responsabilidad y de compromiso, por muy despectivo que sea su lenguaje, que de una relación de propiedad. A pesar de señalar a la naturaleza como proveedora de la fuerza de los hombres, estos muy pocas veces mencionan el destino como el factor que rige sus acciones; en la serie, por lo general Aurelio siempre expresa un factor de decisión propia en cada una de sus elecciones.

El señor de los cielos en todo momento revela la identidad de un hombre sanguinario, narcisista y dispuesto a pasar por encima de cualquiera, pero, al mismo tiempo, es a ese hombre a quien se le atribuyen cualidades que parecen el privilegio de una masculinidad determinada, como capacidad de decisión, aplomo, entereza y el don de conocer la naturaleza humana de quienes lo rodean, como si la inteligencia estuviera irremediablemente unida a la maldad, o como si los mitos más comunes sobre el comportamiento de los sujetos fueran las leyes que rigen la vida. Las narrativas mediáticas construyen determinados patrones de género, y con ello en muchas ocasiones reafirman los estereotipos clásicos sobre la masculinidad y la feminidad. Así, contribuyen de alguna manera a perpetuar esos criterios que invisibilizan y distorsionan, a partir de patrones culturales estáticos, toda una variedad de aspectos, contextos $y$ roles sociales que forman parte de la vida cotidiana y de las relaciones de género.

\section{Referencias bibliográficas}

- Barthes, R. (1991). Mythologies. Nueva York: The Noonday Press.

- Connell, R. (2000). The Men and the Boys. Reino Unido: Polity Press.

- Giddens, A. (1984). The Constitution of Society: Outline of the Theory of Structuration. California: University of California Press.

- Hall, S. (2013). Representation: Cultural Representations and Signifying Practices. Londres. Sage Publications.

- MacKinnon, K. (2003). Representing men. Maleness and masculinity in the media. Londres: Oxford University Press.

\section{Referencia televisiva}

- Aranda, I. y otros. (Productores). (2013-2018). El Señor de Los Cielos [serie de televisión]. Miami, Estados Unidos: Telemundo Studios. 